NBER WORKING PAPERS SERIES

THE COWLES COMMISSION APPROACH, REAL BUSINESS CYCLE THEORIES, AND NEW KEYNESIAN ECONOMICS

Ray C. Fair

Working Paper No. 3990

\author{
NATIONAL BUREAU OF ECONOMIC RESEARCH \\ 1050 Massachusetts Avenue \\ Cambridge, MA 02138 \\ February 1992
}

This paper is part of NBER's research program in Economic Fluctuations. Any opinions expressed are those of the author and not those of the National Bureau of Economic Research. 
NBER Working Paper \#3990

February 1992 THE COWLES COMMISSION APPROACH, REAL BUSINESS CYCLE THEORIES,
AND NEW KEYNESIAN ECONOMICS

\begin{abstract}
The Cowles Commission approach is reviewed and compared to the approaches of real business cycle (RBC) theorists and new Keynesian economists. It is argued that RBC models are not tested in a serious enough way and that the new Keynesian literature is not empirical enough for testing even to be a serious possibility. Macroeconomics seems to be moving away from its traditional empirical basis, which is sad. This paper argues for retuming to the path that was abandoned by most macroeconomists around 1970 , namely the specification and testing of structural macroeconometric models.
\end{abstract}

Ray C. Fair

Cowles Foundation Box 2125, Yale Station

New Haven, CT 06520

and NBER 
Revised February 1992

\section{THE COWLES COMMISSION APPROACH, REAL BUSINESS CYCLE THEORIES, AND NEW KEYNESIAN ECONOMICS ${ }^{1}$}

by

Ray C. Fair

\section{Introduction}

I have been given the daunting task of discussing how the debate among the various schools of business cycle theorists might be resolved. People obviously differ in how they think the macroeconomy works. Will consensus ever be achieved regarding which model best approximates the economy? I am optimistic enough to think so, although I view the last two decades as having made only modest progress in this direction. One problem is that there is too little testing of alternative models. There has been no systematic attempt to try to find the model that best approximates the macroeconomy. As disturbing, however, is the fact that macroeconomic research appears to be moving away from its traditional empirical emphasis. I will elaborate on both of these points in this paper.

From Tinbergen's (1939) model building in the late 1930s through the 1960s, the dominant methodology of macroeconomics was what I will call the "Cowles Commission" approach. ${ }^{2}$ Structural econometric models were specified, estimated, and then analyzed and tested in various ways. One of the major macroeconometric efforts of the 1960 s, building on

\footnotetext{
${ }^{1}$ Presented at "What Do We Know About Business Cycles?", 16th Annual Policy Conference of the Federal Reserve Bank of St. Louis, October 17-18, 1991. I am indebted to my discussant, Arnold Zellner, to other participants at the Conference, and to Al Klevorick for many helpful comments.
}

${ }^{2}$ See Arrow (1991) and Malinvaud (1991) for interesting historical discussions of econometric research at the Cowles Commission (later Cowles Foundation) and its antecedents. 
the earlier work of Klein (1950) and Klein and Goldberger (1955), was the Brookings model (Duesenberry, Fromm, Klein, and Kuh $(1965,1969))$. This model was a joint effort of many individuals, and at its peak it contained nearly 400 equations. Although much was leamed from this exercise, the model never achieved the success that was initially expected, and it was laid to rest around 1972.

Two important events in the 1970 s contributed to the decline in popularity of the Cowles Commission approach. The first was the commercialization of macroeconometric models. ${ }^{3}$ This changed the focus of research on the models. Basic research gave way to the day-to-day needs of keeping the models up to date, of subjectively adjusting the forecasts to make them "reasonable," and of meeting the special needs of clients. The second event was Lucas's (1976) critique, which argued that the models are not likely to be useful for policy purposes.

The Lucas critique led to a line of research that has cumulated in the real business cycle (RBC) theories. This in turn has generated a counter response in the form of new Keynesian economics. I will argue below that neither the RBC approach nor new Keynesian economics is in the spirit of the Cowles Commission approach and that this is a step backward. The Cowles Commission approach is reviewed in Section II, the RBC approach is discussed in Section III, and new Keynesian economics is discussed in Section IV. Suggestions for the future are presented in Section V.

\footnotetext{
${ }^{3}$ It should be noted that the commercialization of models has been less of a problem in the United Kingdom than in the United States. In 1983 the Macroeconomic Modelling Bureau of the Economic and Social Research Council was established at the University of Warwick under the direction of Kenneth F. Wallis. Various U.K. models and their associated databases are made available to academic researchers through the Bureau.
} 


\section{The Cowles Commission Approach}

\section{Specification}

Some of the early macroeconometric models were linear, but they soon gave way to the specification of nonlinear models. Consequently, only the nonlinear case will be considered here. The model will be written as:

(1) $f_{i}\left(y_{t}, x_{t}, \alpha_{i}\right)=u_{i l},(i=1, \ldots, n),(t=1, \ldots, T)$,

where $y_{t}$ is an $n$-dimensional vector of endogenous variables, $x_{t}$ is a vector of predetermined variables (including lagged endogenous variables), $\alpha_{i}$ is a vector of unknown coefficients, and $u_{i t}$ is the error term for equation $i$ for period $t$. For equations that are identities, $u_{i t}$ is identically zero for all $t$.

Specification consists of choosing 1) the variables that appear in each equation with nonzero coefficients, 2) the functional form of each equation, and 3) the probability structure for $u_{i t}$. (In modern times one has to make sufficient stationarity assumptions about the variables to make the time-series econometricians happy. The assumption, either explicit or implicit, of most macroeconometric model building work is that the variables are trend stationary.) Economic theory is used to guide the choice of variables. In most cases there is an obvious left-hand-side variable for the equation, where the normalization used is to set the coefficient of this variable equal to one. This is the variable considered to be "explained" by the equation.

It will be useful to consider an example of how theory is used to specify an equation. Consider the following maximization problem for a representative household. Maximize 
(2) $\mathrm{E}_{0} \mathrm{U}\left(\mathrm{C}_{1}, \ldots, \mathrm{C}_{\mathrm{T}}, \mathrm{L}_{1}, \ldots, \mathrm{L}_{\mathrm{T}}\right)$

subject to

(3) $S_{t}=W_{t}\left(H-L_{t}\right)+r_{t} A_{t-1}-P_{t} C_{t}$,

$A_{t}=A_{t-1}+S_{t}$,

$A_{T}=\vec{A}$,

where $C$ is consumption, $L$ is leisure, $S$ is saving, $W$ is the wage rate, $H$ is the total number of hours in the period, $\mathrm{r}$ is the one-period interest rate, $\mathrm{A}$ is the level of assets, $\mathrm{P}$ is the price level, $\vec{A}$ is the terminal value of assets, and $t=1, \ldots, T$. $E_{0}$ is the expectations operator conditional on information available through time 0 . Given $A_{0}$ and the conditional distributions of the future values of W, $\mathrm{P}$, and $r$, it is possible in principle to solve for the optimal values of $C$ and $L$ for period 1 , denoted $C_{1}^{*}$ and $L_{1}^{*}$. In general, however, this problem is not analytically tractable; it is not generally possible to find analytic expressions for $C_{1}^{*}$ and $L_{1}^{*}$.

The approach that I am calling the Cowles Commission approach can be thought of as specifying and estimating approximations of the decision equations. In the context of the present example this approach proceeds as follows. First, the random variables, $W_{1}, P_{t}$, and $r_{t}, t=1, \ldots, T$, are replaced by their expected values; $E_{0} W_{t}, E_{0} P_{t}$, and $E_{0} r_{1}, t=1, \ldots, T$.

Given this replacement, one can write the expressions for $C_{1}^{*}$ and $L_{1}^{*}$ as

(4) $C_{1}^{*}=g_{1}\left(A_{0}, \bar{A}, E_{0} W_{1}, \ldots, E_{0} W_{T}, E_{0} P_{1}, \ldots, E_{0} P_{T}, E_{0} r_{1}, \ldots, E_{0} r_{T}, \beta\right)$,

(5) $L_{1}^{*}=g_{2}\left(A_{0}, \bar{A}, E_{0} W_{1}, \ldots, E_{0} W_{T}, E_{0} P_{1}, \ldots, E_{0} P_{T}, E_{0} r_{1}, \ldots, E_{0} r_{T}, \beta\right)$, 
where $\beta$ is the vector of parameters of the utility function. Equations (4) and (5) simply state that the optimal values for the first period are a function of 1) the initial and terminal values of assets, 2) the expected future values of the wage rate, the price level, and the interest rate, and 3) the parameters of the utility function. ${ }^{4}$ The functional forms of equations (4) and (5) are not in general known. The aim of the empirical work is to try to estimate equations that are approximations of equations (4) and (5). Experimentation consists in trying different functional forms and in trying different assumptions about how expectations are formed. Because of the large number of expected values in equations (4) and (5), the expectational assumptions usually restrict the number of free parameters to be estimated. For example, the parameters for $E_{0} W_{1}, \ldots, E_{0} W_{T}$ might be assumed to lie on a low order polynomial or to be geometrically declining. The error terms are usually assumed to be additive, as specified in (1) above, and they can be interpreted as approximation errors.

When equations like (4) and (5) are estimated, lagged dependent variables are often used as explanatory variables. Since $C_{0}$ and $L_{0}$ do not appear in (4) and (5), how can one justify the use of lagged dependent variables? It is common to assume that $C_{1}^{*}$ in (4) and $L_{1}^{*}$ in (5) are long-run "desired" values and then to assume that because of adjustment costs, there is only a partial adjustment of actual to desired values. The usual adjustment equation for consumption would be

(6) $\mathrm{C}_{1}-\mathrm{C}_{0}=\lambda\left(\mathrm{C}_{1}^{*}-\mathrm{C}_{0}\right), 0<\lambda<1$,

${ }^{4}$ If information for period 1 is available at the time the decisions are made, then in equations (4) and (5) $E_{0} W_{1}, E_{0} P_{1}$, and $E_{0} r_{1}$ should be replaced by their actual values. 
which adds $C_{0}$ to the estimated equation. This procedure is ad hoc in the sense that the adjustment equation is not explicitly derived from utility maximization. One can, however, assume that there are utility costs to large changes in consumption and leisure and thus put terms like $\left(C_{1}-C_{0}\right)^{2},\left(C_{2}-C_{1}\right)^{2},\left(L_{1}-L_{0}\right)^{2},\left(L_{2}-L_{1}\right)^{2}, \ldots$ in the utility function (2). This would add the variables $C_{0}$ and $L_{0}$ to the right-hand side of equations (4) and (5), which would justify the use of lagged dependent variables in the empirical approximating equations for (4) and (5).

This setup can handle the assumption of rational expectations in the following sense. Let $E_{t-1} y_{2 t+1}$ denote the expected value of $y_{2 t+1}$, where the expectation is based on information through period $t-1$, and assume that $E_{t-1} y_{2 t+1}$ appears as an explanatory variable in equation 1. (Equation 1 might be the equation explaining consumption, and $y_{2}$ might be the wage rate.) If expectations are assumed to be rational, equation 1 can be estimated by either a limited information or a full information technique. In the limited information case $E_{t-1} y_{2 t+1}$ is replaced by $y_{2 t+1}$, and the equation is estimated by Hansen's (1982) generalized method of moments (GMM) procedure. In the full information case the entire model is estimated at the same time by full information maximum likelihood, where the restriction is imposed that the expectations of future values of variables are equal to the model's predictions of the future values. ${ }^{5}$ Again, the parameters of the expected future values might be restricted to reduce the number of free parameters to be estimated.

The specification that has just been outlined does not allow the estimation of "deep structural parameters, " such as the parameters of utility functions, even under the assumption

\footnotetext{
${ }^{5}$ See Fair and Taylor (1983) for a description of this procedure. This procedure is based on the assumption of certainty equivalence, which is only an approximation for nonlinear models.
} 
of rational expectations. Only approximations of the decision equations are being estimated. The specification is thus subject to the Lucas (1976) critique. More will be said about this below. The specification also uses the certainty equivalence procedure, which is strictly valid only in the linear-quadratic setup.

\section{Estimation}

A typical macroeconometric model is dynamic, nonlinear, simultaneous, and has error terms that may be correlated across equations and with their lagged values. A number of techniques have been developed for the estimation of such models. Techniques that do not take account of the correlation of the error terms across equations (limited information techniques) include limited information maximum likelihood and two-stage least squares. Techniques that do account for this correlation (full information techniques) include full information maximum likelihood and three-stage least squares. It is straightforward to modify these techniques for the case in which the error terms follow autoregressive processes. Also, as noted above, the techniques can be modified to implement the assumption of rational expectations.

Computational advances, in both hardware and software, have made the application of these techniques fairly routine. Even full information maximum likelihood when expectations are assumed to be rational appears computationally feasible for most models.

\section{Testing}

Testing has always played a major role in applied econometrics. When an equation is 
estimated, one examines how well it fits the data, if its coefficient estimates are significant and of the expected sign, if the properties of the estimated residuals are as expected, and so on. Equations are discarded or modified if they do not seem very well to approximate the process that generated the data.

Complete models can also be tested, but here things are more complicated. Given 1) a set of coefficient estimates, 2) values of the exogenous variables, 3) values of the error terms, and 4) lagged values of the endogenous variables, a model can be solved for the current values of the endogenous variables. If the solution (simulation) is "static," the actual values of the lagged endogenous variables are used for each period for which the model is solved, and if the solution is "dynamic," the values of the lagged endogenous variables are taken to be the predicted values of the endogenous variables from the previous periods. If one set of values of the error terms is used, the simulation is said to be "deterministic." The expected values of the error terms are usually assumed to be zero, so that in most cases the error terms are set to zero for the solution. A "stochastic" simulation is one in which 1) the error terms are drawn from estimated distributions, 2) the model is solved for each set of draws, and 3) the predicted value of each endogenous variable is taken to be the average of the solution values across the sets of draws.

A standard procedure for evaluating how well a model fits the data is to solve the model by performing a dynamic, deterministic simulation and then compare the predicted values of the endogenous variables with the actual values using the root mean squared error (RMSE) criterion. Other criteria include mean absolute error and Theil's inequality coefficient. If two models are being compared and model A has lower RMSEs for most of 
the variables than model B, this is evidence in favor of model A over model B.

There is always a danger in this business of "data mining," which means specifying and estimating different versions of a model until a good fit has been achieved (say in terms of the RMSE criterion). The danger with this type of searching is that one finds a model that fits well within the estimation period but is in fact a poor approximation of the economy. To guard against this, predictions are many times for periods beyond the end of the estimation period. If a model is poorly specified, it should not predict well outside the period for which it was estimated, even though it may fit well within the period. ${ }^{6}$

One problem with the RMSE criterion is that it does not take account of the fact that forecast-error variances vary across time. Forecast-error variances vary across time because of nonlinearities in the model and variation in the exogenous variables. Although RMSEs are in some loose sense estimates of the averages of the variances across time, no rigorous statistical interpretation can be placed on them: they are not estimates of any parameters of a model.

A more serious problem with the RMSE criterion as a means of comparing models is that models may be based on different sets of exogenous variables. If one model takes investment as exogenous and a second does not, the first model has an unfair advantage when computing RMSEs.

\footnotetext{
${ }^{6}$ This assumes that one does not search by 1) estimating a model up to a certain point, 2) solving the model for a period beyond this point, and 3 ) choosing the version that best fits the period beyond the point. If this were done, then one would have to wait for more observations to provide a good test of the model. Even if this type of searching is not formally done, it may be that information beyond the estimation period has been implicitly used in specifying a model. This might then lead to a better fit beyond the estimation period than is wartanted. In this case, one would also have to wait for more observations to see how accurate the model in fact is.
} 
I have developed a method, based on stochastic simulation, that accounts for the RMSE difficulties (Fair (1980)). The method accounts for the four main sources of uncertainty of a forecast from a model: uncertainty due to 1) the error terms, 2) the coefficient estimates, 3) the exogenous variables, and 4) the possible misspecification of the model. The forecast-error variance for each variable and each period estimated by the method accounts for all four sources of uncertainty, and so it can be compared across models. The estimated variances from different structural models can be compared, or the estimated variances from one structural model can be compared to those from an autoregressive or vector autoregressive model. If a particular model's estimated variances are in general smaller than estimated variances from other models, this is evidence in favor of the particular model.

A by-product of the method is an estimate of the degree of misspecification of a model for each endogenous variable. Any model is likely to be somewhat misspecified, and the method can estimate the quantitative importance of the misspecification.

The method can encompass a variety of assumptions about exogenous-variable uncertainty. One polar assumption is that there is no uncertainty attached to the exogenous variables. This might be true, for example, of some policy variables. The other polar assumption is that the exogenous variables are in some sense as uncertain as the endogenous variables. One can, for example, estimate autoregressive equations for each exogenous variable and add these equations to the model. This would produce a model with no exogenous variables, which could then be tested. An in-between case would include estimating the variance of an exogenous-variable forecast error from actual forecasting errors 
made by a forecasting service -- say the errors made by DRI in forecasting defense spending. Another method of comparing models is to regress the actual value of an endogenous variable on a constant and forecasts of the variable from two or more models. This procedure is explained in Fair and Shiller (1990) and is related to the literature on encompassing tests -- see, for example, Davidson and MacKinnon (1981), Hendry and Richard (1982), and Chong and Hendry (1986). Again, one can use autoregressive or vector autoregressive models as comparisons for structural models using these tests.

Testing models in the ways described seems clearly in the spirit of the Cowles Commission approach. A model to the Cowles Commission was a null hypothesis to be tested.

\section{A Digression on Monetarism}

Laidler (1991) has written an interesting and useful paper on the history of monetarism for this conference. From the perspective of the Cowles Commission approach, I have no complaints about this paper. The Laidler and Bentley (1983) model, for example, is a standard macroeconometric model, and it can be tested in the ways discussed above. In fact, in Laidler's last sentence he states that he hopes to "reinstate empirical evidence as a factor more important than a priori principles" in the debate about business cycles. I would interpret this as an argument for the Cowles Commission approach.

This is not to say, however, that I would argue in favor of the Laidler and Bentley model. Although in simple tests the model does about the same as Barro's (1978) model, I doubt that it would hold up well against larger structural models or even against 
autoregressive and vector autoregressive models. But the main point is that the model can be tested. The debate is simply about which macroeconometric model -- a model in the monetarist spirit or some other model -- best explains the data.

\section{The Real Business Cycle Approach}

In discussing the RBC approach, it will be useful to begin with the utility maximization model described in Section II. The RBC approach to this model would be to specify a particular functional form for the utility function in (2). The parameters of this function would then be either estimated or simply chosen ("calibrated") to be in line with parameters estimated in the literature.

Although there is some parameter estimation in the RBC literature, most of the studies calibrate rather than estimate, in the spirit of the seminal article by Kydland and Prescott (1982). If the parameters are estimated, they are estimated from the first order conditions. A recent example is Christiano and Eichenbaum (1990), where the parameters of the model are estimated using Hansen's (1982) GMM procedure. Altug (1989) estimates the parameters of her model using a likelihood procedure. Chow (1991) and Canova, Finn, and Pagan (1991) contain interesting discussions of the estimation of RBC models. There is also a slightly earlier literature in which the parameters of a utility function of the type in (2) were estimated from the first order conditions - see, for example, Hall (1978), Hansen and Singleton (1982), and Mankiw, Rotemberg, and Summers (1985).

The RBC approach meets the Lucas critique; deep structural parameters are being estimated (or calibrated). It is hard to overestimate the appeal this has to many people. 
Anyone who doubts this appeal should read Lucas' 1985 Jahnsson lectures (Lucas (1987)), which make an elegant argument for dynamic economic theory. The tone of these lectures is that there is an exciting sense of progress in macroeconomics and that there is hope that in the end there will be essentially no distinction between microeconomics and macroeconomics. There will simply be economic theory applied to different problems.

Once the coefficients are chosen, by whatever means, the overall model can be solved. In the utility maximization example, one could solve for the optimal consumption and leisure paths. The properties of the computed paths of the decision variables are then compared to the properties of the actual paths of the variables. If the computed paths have properties similar to the actual paths (e.g., similar variances, covariances, and autocovariances), this is judged to be a positive sign for the model. If the parameters are chosen by calibration, there is usually some searching over parameters to find that set that gives good results in matching the computed paths to the actual paths in terms of the particular criterion used. In this sense the calibrated parameters are also estimated.

Is the RBC approach a good way of testing modeis? At first glance it might seem so, since computed paths are being compared to actual paths. But the paths are being compared in a very limited way relative to the way that the Cowles Commission approach would compare them. Take the simple RMSE procedure. This procedure would compute a prediction error for a given variable for each period and then calculate the RMSE from these prediction errors. This RMSE might then be compared to the RMSE from another structural model or from an autoregressive or vector autoregressive model. 
I have never seen this type of comparison done for a RBC model. How would, say, the currently best fitting RBC model compare to a simple first order autoregressive equation for real GNP in terms of the RMSE criterion? My guess is very poorly. Having the computed path mimic the actual path for a few selected moments is a far cry from doing better than even a first order autoregressive equation (let alone a structural model) in terms of fitting the observations well according to the RMSE criterion. The disturbing feature of the RBC literature is that there seems to be no interest in computing RMSEs and the like. People generally seem to realize that the RBC models do not fit well in this sense, but they proceed anyway.

If this literature proceeds anyway, it has in my view dropped out of the race. The literature may take a long time to play itself out, but it will eventually reach a dead end unless it comes around to developing models that can compete with others in explaining the economy observation by observation.

One of the main reasons that people proceed anyway is undoubtedly the Lucas critique and the general excitement about deep structural parameters. Why waste one's time by working with models whose coefficients change over time as policy rules and other things change? The logic of the Lucas critique is certainly correct, but the key question for empirical work is the quantitative importance of this critique. Even the best econometric model only approximates how the economy works. Another potential source of coefficient change is the use of aggregate data. As the age and income distributions of the population change, the coefficients in aggregate equations are likely to change, and this is a source of error in the estimated equations. This problem may be quantitatively much more important 
than the problem raised by Lucas. Put another way, the representative agent model that is used so much in macroeconomics has serious problems of its own, and these problems may completely swamp the problem of coefficients changing when policy rules change. The RBC literature has focused so much on solving one problem that it is likely in the process to have exacerbated the effects of a number of others.

There are a number of reasons the RBC models probably do not fit the data well. The RBC approach requires that a particular functional form be chosen for, say, the utility function, and errors made in this choice may lead to large prediction errors. Remember that this function represents the average of the utility functions of all the households in the economy, and it is unlikely that one is going to get this quite right. The advantage of estimating approximations of the decisions equations, as discussed in Section II, is that it allows more flexibility in estimating functional forms. The data are allowed more play, if you will. By estimating approximations of decision equations one trades off estimating deep structural parameters for less sensitivity to functional-form errors and the like.

When deep structural parameters have been estimated from the first order conditions, the results have not always been very good in terms of getting estimates that seen sensible. The results in Mankiw, Rotemberg, and Summers (1985) for the utility parameters are not supportive of the approach. In a completely different literature - the estimation of production-smoothing equations - Krane and Braun (1989), whose study is based on quite good data, report that their attempts to estimate first order conditions were unsuccessful. It may be asking too much of the aggregate data to force them into estimating parameters from some postulated function. 
Finally, one encouraging feature of the Lucas critique is that it can be tested. Assume that the parameters of an equation or set of equations the parameters change considerably when a given policy variable changes. Assume also that the policy variable changes frequently. In this case the model is misspecified, so that methods like the one discussed in Section II should be able to detect this misspecification if the policy variable has changed frequently. If the policy variable has not changed or has changed very little, then the model will be misspecified, but the misspecification will not be given a change to be detected in the data. Otherwise, models that suffer in an important way from the Lucas critique ought to be weeded out by various tests.

\section{The New Keynesian Economics}

After reading or rereading a number of new Keynesian articles in preparing this paper, I came away feeling uneasy. It's like coming out of a play that many of your friends liked and feeling that you did not really like it, but not knowing quite why. Given my views of how the economy works, many of the results of the new Keynesian literature seem reasonable, but something seemed missing. One problem is that it is hard to see a big picture. There are many small stories, and it's hard to remember each one. In addition, many of the conclusions do not seem robust to small changes in the models.

On further reflection, however, 1 do not think this was my main source of uneasiness. The main problem is that this literature is not really empirical in the Cowles Commission sense. This literature has moved macroeconomics away from its econometric base.

Consider, for example, the articles in the two volumes of New Keynesian Economics, edited 
by Mankiw and Romer (1991). By my count, of the 34 papers in these two volumes, only 8 have anything to do with data. ${ }^{7}$ Of these 8 , one (Carlton, "The Rigidity of Prices") is more industrial organization than macro and one (Krueger and Summers, "Efficiency Wages and the Interindustry Wage Structure") is more labor than macro. These two studies provide some interesting insights that might be of help to macroeconomists, but they are not really empirical macroeconomics.

It has been pointed out to $\mathrm{e}^{8}$ that the Mankiw and Romer volumes may be biased against empirical papers because of space constraints imposed by the publisher. Nevertheless, it seems clear that there is very little in the new Keynesian literature in the nature of structural modeling of the kind outlined in Section II above. As in the RBC literature, one does not see, say, predictions of real GNP from some new Keynesian model compared to predictions of real GNP from an autoregressive equation using a criterion like the RMSE criterion. But here one does not see it because no econometric models of real GNP are constructed! This literature has dropped out of the race not because it is necessarily uninterested in serious tests but because it is uninterested in constructing econometric models.

I should hasten to add that I do not mean by the above criticisms that there is no interesting empirical work going on in macroeconomics. For example, the literature on production-smoothing, which is largely empirical, has produced some important results and insights. It is simply that literature of this type is not generally classified as new Keynesian. Even if one were generous and put some of this empirical work in the new Keynesian

\footnotetext{
${ }^{7}$ One might argue that the number is 9. Okun's article "Inflation: Its Mechanics and Welfare Costs," which I did not count in the 8, presents and briefly discusses data in one figure.

${ }^{8}$ By Olivier Blanchard.
} 
literature, it is surely not the essence of new Keynesian economics.

One might argue that new Keynesian economics is just getting started and that the big picture (model) will eventually emerge to rival existing models of the economy. This is probably an excessively generous interpretation, given the focus of this literature on small theoretical models. But unless the literature does move in a more econometric and largermodel direction, it is not likely to have much long-run impact.

\section{Looking Ahead}

I see the RBC and new Keynesian literatures passing each other like two runners in the night, both having left the original path laid out by the Cowles Commission and its predecessors. To answer the question posed to me at this conference, I see no way to resolve the debates between these two literatures. The RBC literature is interested in testing in only a very limited way, and the new Keynesian literature is not econometric enough to even talk about serious testing.

But I argue there is hope. Models can be tested, and there are procedures for weeding out inferior models. The RBC literature should entertain the possibility of testing models based on estimating deep structural parameters against models based on estimating approximations of decision equations. Also, the tests should be more than just observing whether a computed path mimics the actual path in a few ways. The new Keynesian literature should entertain the possibility of putting its various ideas together to specify, estimate, and test structural macroeconometric models. 
Finally, both literatures ought to consider bigger models. I have always thought it ironic that one of the consequences of the Lucas critique was to narrow the number of endogenous variables in a model from many (say a hundred or more) to generally no more than three or four. If one is worried about coefficients in structural equations changing, it seems unlikely that getting rid of the structural detail in large-scale models is going to get one closer to deep structural parameters. 


\section{REPERENCES}

Altug, Sumru, "Time-to-Build and Aggregate Fluctuations: Some New Evidence," Intemational Economic Review, 30, 1989, 889-920.

Arrow, Kenneth J., "Cowles in the History of Economic Thought," in Cowles Eiftieth Anniversary, Yale University, 1991.

Barro, Robert J., "Unanticipated Money, Output, and the Price Level in the United States," Joumal of Political Economy, 86, 1978, 549-581.

Canova, F., M. Finn, and A.R. Pagan, "Econometric Issues in the Analysis of Equilibrium Models, " paper given at the Canadian Econometric Study Group meeting, Quebec City, September 1991.

Chong, Yock Y., and David F. Hendry, "Econometric Evaluation of Linear MacroEconometric Models," Review of Economic Studies, 53, 1986, 671-690.

Chow, Gregory C., "Statistical Estimation and Testing of a Real Business Cycle Model," mimeo, August 30, 1991.

Christiano, Lawrence J., and Martin Eichenbaum, "Current Real Business Cycle Theories and Aggregate Labor Market Fluctuations," Discussion Paper 24, Institute for Empirical Macroeconomics, January 1990.

Davidson, Russell, and James G. MacKinnon, "Several Tests of Model Specification in the Presence of Alternative Hypotheses," Esonometrica, 40, 1981, 781-793.

Duesenberry, James S., Gary Fromm, Lawrence R. Klein, and Edwin Kuh, eds., The Brookings Ouarterly Econometric Model of the United States, Chicago: Rand McNally \& Company, 1965.

Duesenberry, James S., Gary Fromm, Lawrence R. Klein, and Edwin Kuh, eds., The Brookings Model: Some Further Results, Chicago: Rand McNally \& Company, 1969.

Fair, Ray C., "Estimating the Expected Predictive Accuracy of Econometric Models," International Economic Review, 21, 1980, 355-378.

Fair, Ray C., and Robert J. Shiller, "Comparing Information in Forecasts from Econometric Models," American Economic Review, 80, 1990, 375-389.

Fair, Ray C., and John Taylor, "Solution and Maximum Likelihood Estimation of Dynamic Rational Expectations Models," Econometrica, 51, 1983, 1169-1185. 
Hall, Robert E., "Stochastic Implications of the Life-Cycle Permanent Income Hypothesis: Theory and Evidence," Loumal of Political Economy, 86, 1978, 971-989.

Hansen, Lars Peter, "Large Sample Properties of Generalized Method of Moments Estimators," Econometrica, 50, 1982, 1029-1054.

Hansen, Lars Peter, and Kenneth Singleton, "Generalized Instrumental Variables Estimation of Nonlinear Rational Expectations Models, " Econometrica, 50, 1982, 1269-1286.

Hendry, David F., and Jean-Francois Richard, "On the Formulation of Empirical Models in Dynamic Economics," Journal of Econometrics, 20, 1982, 3-33.

Klein, Lawrence R., Economic Fluctuations in the United States, 1921-1941, New York: Wiley, Cowles Monograph No. 11, 1950.

Klein, Lawrence R., and Arthur S. Goldberger, An Econometric Model of the United States 1922-1952, Amsterdam: North-Holland, 1955.

Krane, Spencer D., and Steven N. Braun, "Production Smoothing Evidence from PhysicalProduct Data," mimeo, 1989.

Kydland, F.E., and E.C. Prescott, "Time To Build and Aggregate Fluctuations," Econometrica, 50, 1982, 1345-1370.

Laidler, David, "The Cycle Before New-Classical Economics," paper presented for this conference, 1991.

Laidler, David, and B. Bentley, "A Small Macro-model of the Post-war United States," Manchester School, 51 (1983), 317-340.

Lucas, Robert E., Jr., "Econometric Policy Evaluation: A Critique," in K. Brunner and A.H. Meltzer, eds, The Phillios Curve and Labor Markets, Amsterdam: North-Holland, 1976.

Lucas, Robert E., Jr., Models of Business Cycles, New York: Blackwell, 1987.

Malinvaud, Edmond, "Econometric Methodology at the Cowles Commission: Rise and Maturity," in Cowles Fiftieth Anniversary, Yale University, 1991.

Mankiw, N. Gregory, and David Romer (eds.), New Keynesian Economics, Volumes 1 and 2, Cambridge: MIT Press, 1991. 
Mankiw, N. Gregory, Julio J. Rotemberg, and Laurence H. Summers, "Intertemporal Substitution in Macroeconomics," Quarterly Joumal of Economics, 100, 1985, 225 251.

Tinbergen, J., Statistical Testing of Business Cycle Theories, Geneva: League of Nations, 1939. 